ARTICLE

Received 8 Jul 2013 | Accepted 1 Oct 2013 | Published 29 Oct $2013 \quad$ DOl: 10.1038/ncomms3694

\title{
Synthesis and physical properties of a ball-like three-dimensional $\pi$-conjugated molecule
}

\author{
Eiichi Kayahara1,2, Takahiro Iwamoto ${ }^{1}$, Hikaru Takaya', Toshiyasu Suzuki ${ }^{2,3}$, Mamoru Fujitsuka ${ }^{2,4}$,
} Tetsuro Majima ${ }^{2,4}$, Nobuhiro Yasuda ${ }^{5}$, Naoto Matsuyama ${ }^{6}$, Shu Seki ${ }^{6} \&$ Shigeru Yamago ${ }^{1,2}$

Curved $\pi$-conjugated molecules with closed and three-dimensional (3D) structures, such as fullerenes and carbon nanotubes, have been the subject of intensive research due to their potential applications in molecular electronics. However, basic molecular skeletons of 3D molecules are limited because of the lack of a rational and selective synthetic method by organic synthesis. Here we report the synthesis of a 3D $\pi$-conjugated molecule based on the platinum-mediated assembly of four molecules of a stannylated trisubstituted benzene derivative forming a hexanuclear platinum complex with an octahedral shape, from which reductive elimination of platinum gave the target molecule. As many supramolecular transition metal-ligand complexes with 3D cages and polyhedral structures have been synthesized by self-assembly of ligands and metals, the current assembly/reductive elimination strategy could provide a variety of new 3D $\pi$-conjugated molecules with different structures and topologies, which are challenging to obtain using conventional synthetic methods.

\footnotetext{
${ }^{1}$ Institute for Chemical Research, Kyoto University, Uji 611-0011, Japan. ${ }^{2}$ CREST, Japan Science and Technology Agency, Tokyo 102-0076, Japan. ${ }^{3}$ Institute for Molecular Science, National Institute of Natural Sciences, Myodaiji, Okazaki 444-8787, Japan. ${ }^{4}$ The Institute of Scientific and Industrial Research, Osaka University, Ibaraki, Osaka 567-0047, Japan. ${ }^{5}$ Research and Utilization Division, Japan Synchrotron Radiation Research Institute, Hyogo 679-5198, Japan. ${ }^{6}$ Department of Applied Chemistry, Osaka University, Suita, Osaka 565-0871, Japan. Correspondence and requests for materials should be addressed to S.Y. (email: yamago@scl.kyoto-u.ac.jp).
} 
A fter the discovery of fullerenes ${ }^{1}$ and carbon nanotubes $(\mathrm{CNTs})^{2}$, curved $\pi$-conjugated molecules with closed and three-dimensional (3D) structures have been the subject of intensive research. This is not only for their structural beauty but also their many potential applications in molecular electronics ${ }^{3,4}$. For example, $\mathrm{C}_{60}$ and $\mathrm{C}_{70}$ derivatives have been used as charge transport materials in organic photovoltaics ${ }^{5,6}$, and CNTs have demonstrated promise as nanowires or active components in electronic devices such as the field-effect transistor ${ }^{7}$. However, despite these developments, basic molecular skeletons of 3D molecules are limited. This is due to the lack of a rational synthetic method, with fullerenes and CNTs being prepared by physical methods such as laser vaporization or arc discharge of carbon and combustion of aromatic hydrocarbons. A solitary exception is the rational synthesis of $\mathrm{C}_{60}$ by Scott et al. ${ }^{8}$, which was based on a flash vacuum pyrolysis technique. However, the application of this strategy to other 3D molecules has been hampered owing to the low generality, long synthetic steps, harsh reaction conditions and poor overall yields. Therefore, development of a general, bottom-up synthetic route to $3 \mathrm{D} \pi$-conjugated molecules by organic synthesis is not only a significant challenge but also a pivotal contribution to materials science.

Recently, two-dimensional (2D) hoop-shaped $\pi$-conjugated molecules, in particular cycloparaphenylenes (CPPs), the simplest structural unit of armchair CNTs, have captured significant interest $^{9}$, and three groups including our own have developed new synthetic methods for producing them ${ }^{10-17}$. Our method relies on the formation of a square-shaped tetranuclear aryl platinum complex by the transmetallation of arylmetal species and a platinum dihalide (Fig. 1a) ${ }^{12,18-20}$. The process of the complex formation can be regarded as a covalent bonding<smiles>[M]C1CCC(C)C(c2ccc(C)cc2)C1</smiles>

b

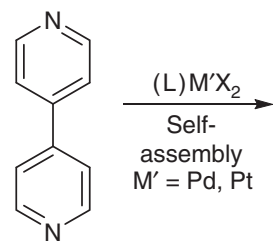

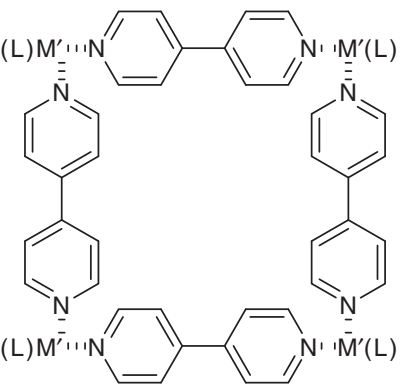

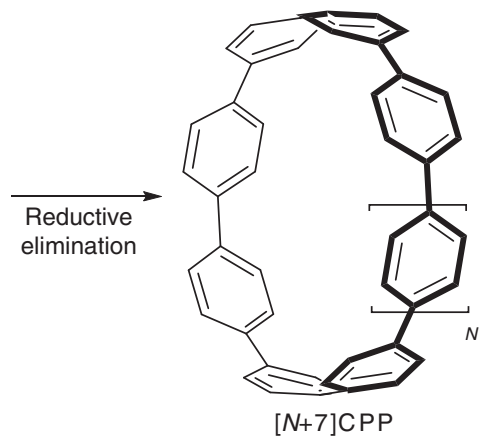

$[N+7] C P P$

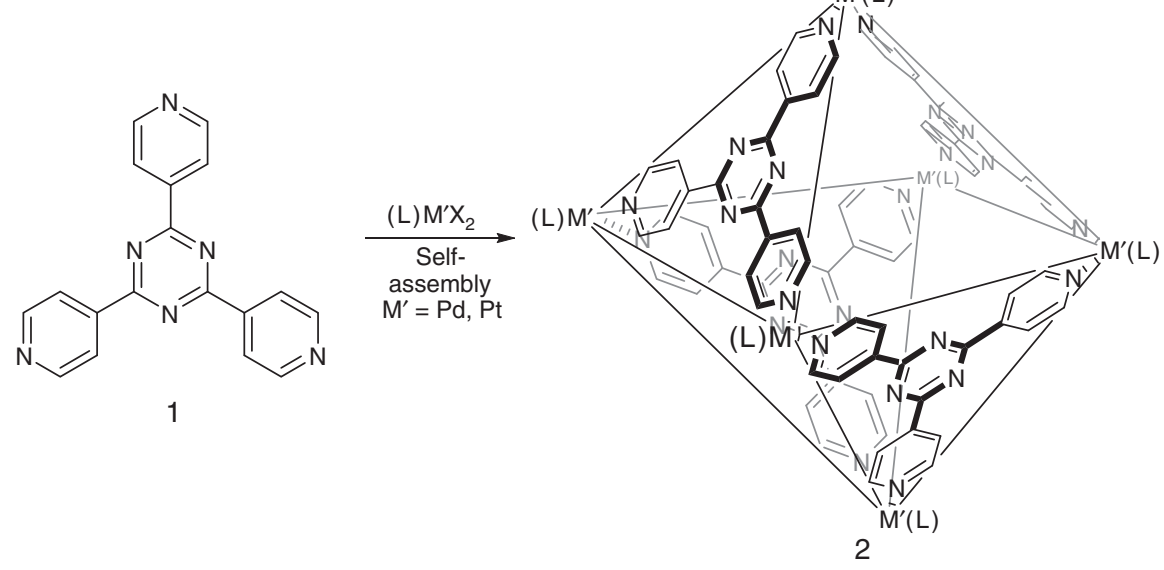

Figure 1 | Cycloparaphenylene and supramolecular transition metal-ligand complexes. (a) Synthetic route of cycloparaphenylenes (CPPs). (b) Selfassembly of metal-ligand interaction forming square metal complex. (c) Octahedral metal complex. M, metal; L, ligand. 
version of the self-assembly of structurally related coordination complexes of palladium and platinum macrocycles with, for example 4,4'-bipyridyl, in supramolecular chemistry (Fig. 1b) ${ }^{21-23}$. Once the covalently bonded complex has been formed, reductive elimination of platinum affords the CPPs.

As many supramolecular transition metal-ligand complexes with $3 \mathrm{D}$ cages and polyhedral structures have been previously reported $^{24-27}$, it was envisioned that these complexes would be suitable precursors for $3 \mathrm{D}$ molecules. For example, Fujita ${ }^{24}$ reported that trispyridyl ligand $\mathbf{1}$ and palladium(II) selectively and quantitatively formed octahedral, hexapalladium cage 2 by self-assembly involving a ligand-metal interaction. If a structurally related cage consisting solely of covalent bonds was to form, such a molecule would be a possible precursor of a 3D $\pi$-conjugated molecule.

Here we report the synthesis of a $3 \mathrm{D}$, spherical $\pi$-conjugated molecule, in which $\mathrm{sp}^{2}$-carbons of 1,3,5-trisubstituted and 1,4disubstituted benzenes are covalently bonded forming a ball-like molecule. The synthesis involves the assembly of four molecules of tristannylated 1,3,5-benzene derivative and six platinum(II) species through 12-fold stannane-platinum transmetallation forming a hexanuclear platinum complex with octahedral shape, from which 6-fold reductive elimination of platinum gave the target molecule. The structure of the molecule is unambiguously determined by the single-crystal X-ray analysis. In addition, the optical and electrochemical properties and charge mobility of the molecule are reported.

\section{Results}

Synthesis of 3D molecule 3. The synthesis of 3D molecule 3 starting from commercially available tribromide $\mathbf{4 a}$ is summarized in Fig. 2. Transmetallation of the bromide in $\mathbf{4 a}$ by $\mathrm{BuLi}$, followed by the addition of trimethylstannyl chloride, gave $\mathbf{4 b}$, which was treated with 3 equiv. of $\mathrm{Pt}(\operatorname{cod}) \mathrm{Cl}_{2}(\operatorname{cod}=1,5$ cyclooctadiene) in 1,2 -dichloroethane at $50^{\circ} \mathrm{C}$ for $20 \mathrm{~h}$, affording trisplatinated $4 \mathbf{c}$ in $75 \%$ yield (two steps). Subsequently, $4 \mathbf{c}$ was treated with an equimolar amount of $\mathbf{4 b}$ in 1,2-dichloroethane $(1 \mathrm{mM})$ at $50^{\circ} \mathrm{C}$ for $30 \mathrm{~h}$. The white precipitate that was formed was collected by filtration and washed with 1,2-dichloroethane and toluene to afford $\mathbf{5 d}$ in $81 \%$ yield. The structure of $\mathbf{5 d}$ was characterized by ${ }^{1} \mathrm{H}$ and ${ }^{13} \mathrm{C}$ NMR spectroscopies. The formation of $\mathbf{5 d}$ is most likely to involve reversible C-Pt bond formation ${ }^{18}$, but the detail studies were hampered due to the low solubility of 5d. Treatment of 5d with bis(diphenylphosphino)ferrocene (dppf, 6 equiv.) gave 5e. After removal of cod and unreacted dppf, treatment of the reaction mixture with $\mathrm{XeF}_{2}$ (6 equiv.) in toluene at $90^{\circ} \mathrm{C}$ for $20 \mathrm{~h}$ gave 3 (refs 20,28 ), which was isolated by silica gel chromatography in $21 \%$ yield as a pale yellow solid. Using triphenylphosphine (6 equiv.) instead of $\mathrm{XeF}_{2}$ also gave $\mathbf{3}$, but in $19 \%$ yield. The use of bromine, however, which was employed in the synthesis of CPPs ${ }^{12,18}$, did not give the desired cyclic product at all. 3 was found to be soluble in many common solvents, including toluene, THF, $\mathrm{CHCl}_{3}$ and $\mathrm{CH}_{2} \mathrm{Cl}_{2}$.

The use of Pt complex was essential to obtain the octahedral complex. The use of Pd complex such as $\mathrm{Pd}(\mathrm{dppf}) \mathrm{Cl}_{2}$ instead of the Pt complex resulted in a complex mixture because bis-aryl Pd complexes readily undergo reductive elimination and do not have sufficient lifetime to form the octahedral complex.

The reductive elimination process was monitored by the ${ }^{19} \mathrm{~F}$ and ${ }^{31} \mathrm{P}$ NMR spectroscopy (Supplementary Figs S1 and S2). When $\mathrm{XeF}_{2}$ (6 equiv.) was added to $\mathbf{5 e}$ in toluene- $\mathrm{d}_{8}$, the reaction mixture immediately turned orange. The ${ }^{19} \mathrm{~F}$ NMR spectrum of the solution showed a singlet peak at -271.3 parts per million (p.p.m.), suggesting the formation of single species. In the ${ }^{31} \mathrm{P}$ NMR spectrum, the singlet peak of $5 \mathbf{e}$ at 20.3 p.p.m. with a characteristic ${ }^{195} \mathrm{Pt}$ satellite $\left({ }^{1} J_{\mathrm{PtP}}=1,784.3 \mathrm{~Hz}\right)$ completely disappeared and a new singlet peak at -2.9 p.p.m. with the satellite $\left({ }^{1} J_{\mathrm{PtP}}=1,018.0 \mathrm{~Hz}\right)$ appeared. The large upfield shift and smaller ${ }^{1} J_{\mathrm{PtP}}$ coupling constant of the product as compared with $\mathbf{5 e}$ suggested the formation of the corresponding (bis-aryl) $\mathrm{Pt}(\mathrm{IV}) \mathrm{F}_{2}$ complex by the oxidation of $\mathbf{5 e}$ by $\mathrm{XeF}_{2}$ (refs 28-30).

After heating at $90^{\circ} \mathrm{C}$ for $3 \mathrm{~h}$, the ${ }^{19} \mathrm{~F}$ NMR analysis indicated the complete disappearance of the signal at -271.3 p.p.m. and the appearance of a new singlet peak at -233.1 p.p.m. corresponding to $\mathrm{Pt}(\mathrm{dppf}) \mathrm{F}_{2}$ together with several peaks from -290 to -236 p.p.m. The spectrum became simpler after $9 \mathrm{~h}$ of heating, and only the signal of $\mathrm{Pt}(\mathrm{dppf}) \mathrm{F}_{2}$ was observed after $18 \mathrm{~h}$. The same trend was observed in the ${ }^{31} \mathrm{P}$ NMR spectrum. The signal at -2.9 p.p.m. almost disappeared after $3 \mathrm{~h}$ with the formation of several new signals, and only a signal corresponding to $\mathrm{Pt}(\mathrm{dppf}) \mathrm{F}_{2}$ was observed at 9.5 p.p.m. with the satellite $\left({ }^{1} J_{\mathrm{PtP}}=3,542.3 \mathrm{~Hz}\right)$ after $18 \mathrm{~h}$ of heating. These observations suggest that the reductive elimination from the initially formed (bis-aryl) $\mathrm{Pt}(\mathrm{IV}) \mathrm{F}_{2}$ to $\mathbf{3}$ did not proceed at the same time but rather in a stepwise manner.

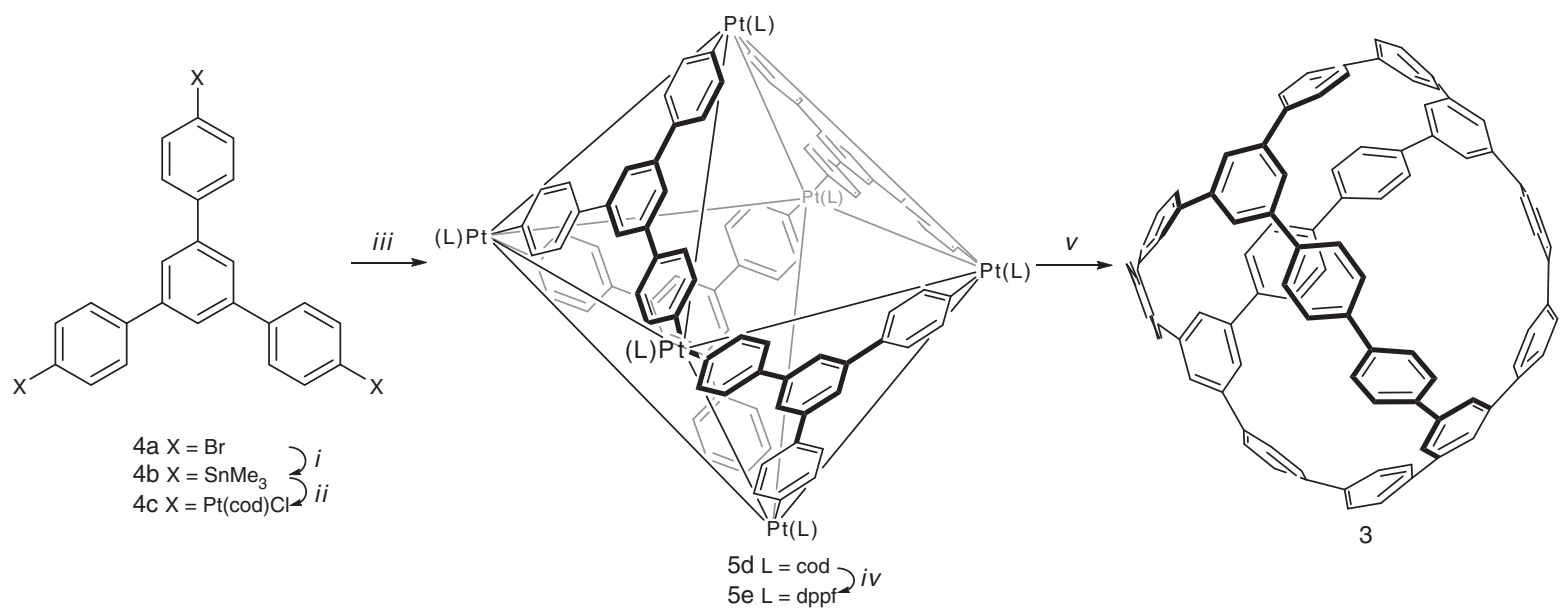

Figure 2 | Synthesis of 3. Reagents and conditions: (i) (1) BuLi (4.5 equiv.), $\mathrm{THF},-78^{\circ} \mathrm{C}, 1 \mathrm{~h} .(2) \mathrm{Me} 3 \mathrm{SnCl}\left(4.5\right.$ equiv.), $-78^{\circ} \mathrm{C}$ to room temperature, $6 \mathrm{~h}$, 91\%. (ii) $\mathrm{Pt}(\mathrm{cod}) \mathrm{Cl}_{2}$ (3.0 equiv.), 1,2-dichloroethane, $50^{\circ} \mathrm{C}, 20 \mathrm{~h}, 82 \%$. (iii) $\mathbf{4 b}$ (1.0 equiv.), 1,2-dichloroethane, $50{ }^{\circ} \mathrm{C}, 30 \mathrm{~h}, 81 \%$. (iv) dppf (6.0 equiv.), $\mathrm{CH}_{2} \mathrm{Cl}_{2}, \mathrm{rt}, 19 \mathrm{~h}, 86 \%$. (v) $\mathrm{XeF}_{2}\left(6.0\right.$ equiv.), toluene, $90^{\circ} \mathrm{C}, 20 \mathrm{~h}, 21 \%$, or $\mathrm{PPh}_{3}\left(6.0\right.$ equiv.), toluene, $90^{\circ} \mathrm{C}, 20 \mathrm{~h}, 19 \%$. cod, 1,5 -cyclooctadiene; dppf, bis(diphenylphosphino)ferrocene. 
Characterization of 3 . The product was first characterized in solution by NMR spectroscopy (Supplementary Figs S3 and S4). In the ${ }^{1} \mathrm{H}$ NMR spectrum in $\mathrm{CDCl}_{3}$ at $25^{\circ} \mathrm{C}, 3$ showed one singlet and two doublets in the aromatic region (7.41, 7.54 and 7.59 p.p.m.), which is consistent with the highly symmetrical structure of 3 . This was also confirmed by the ${ }^{13} \mathrm{C}$ NMR spectrum, which showed six signals $(125.5,127.4,128.3,138.6,139.5$ and 141.9 p.p.m.). In the MALDI-TOF mass spectrum, a molecular ion peak was observed at $m / z=1,212.4612$, with an isotopic distribution pattern identical to the theoretical pattern (Supplementary Fig. S5). The Raman spectrum of $\mathbf{3}$ in THF at room temperature shows a similar spectral pattern to that of $\mathrm{CPPs}^{31}$, but with approximately double the number of peaks present (Supplementary Fig. S6). In addition to the peak derived from the paraphenylene unit, 3 showed the characteristic bands at $1,586,1,329$ and $1,231 \mathrm{~cm}^{-1}$ due to intra-ring $\mathrm{C}-\mathrm{C}$ stretch, interring $\mathrm{C}-\mathrm{C}$ stretch and in-plane $\mathrm{C}-\mathrm{H}$ bend, respectively, derived from the 1,3,5-trisubstituted benzene unit.

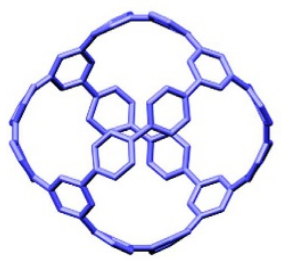

$D_{2}\left(0.0 \mathrm{~kJ} \mathrm{~mol}^{-1}\right)$

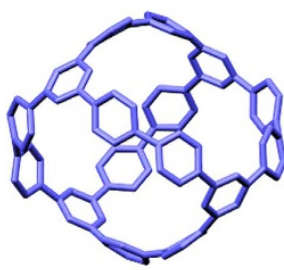

$C_{2}\left(16.2 \mathrm{~kJ} \mathrm{~mol}^{-1}\right)$

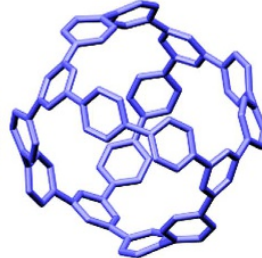

$S_{4}\left(5.3 \mathrm{~kJ} \mathrm{~mol}^{-1}\right)$

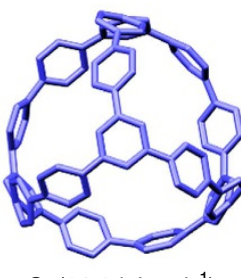

$C_{3}\left(21.8 \mathrm{~kJ} \mathrm{~mol}^{-1}\right)$

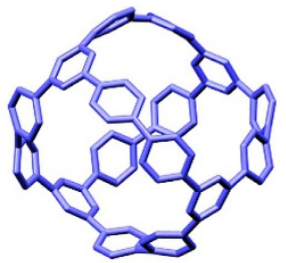

$C_{1}\left(16.0 \mathrm{~kJ} \mathrm{~mol}^{-1}\right)$

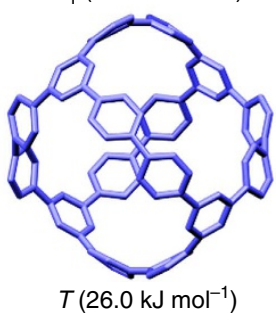

Figure 3 | Calculated structural isomers of 3. All molecular geometries were obtained by geometry optimization with DFT calculation at the B3LYP/ $6-31 \mathrm{G}^{\star}$ level. The energy values $\left(\mathrm{kJ} \mathrm{mol}^{-1}\right)$ beneath each isomer are the relative energy with respect to the lowest-lying isomer calculated at the corresponding level of DFT calculation. Blue represents carbon atoms. Hydrogen atoms are omitted for clarity.
3D-structural information for 3 was first obtained by the density functional theory (DFT) calculations at the B3LYP/6$31 G^{\star}$ level of theory. Six energy-minimized isomers with $D_{2}, S_{4}$, $C_{1}, C_{2}, C_{3}$ and $T$ symmetries were calculated (Fig. 3), among which the $D_{2}$ symmetric isomer was the most thermodynamically stable, followed by the $S_{4}$ symmetric isomer by $5.3 \mathrm{~kJ} \mathrm{~mol}^{-1}$. The other isomers were found to be very high in energy ( $>16.0 \mathrm{~kJ} \mathrm{~mol}^{-1}$ ) compared with the $D_{2}$ isomer, suggesting that the contributions of these isomers to the ground state structure were negligible. As all isomers are rotational isomers with respect to the biphenyl units, the conversion among the isomers should occur spontaneously within the time frame of the NMR measurement. Indeed, the isomerization could not be frozen, even at low temperature, which was evident from the observation that the ${ }^{1} \mathrm{H}$ NMR signals of 3 did not split, even at $-80^{\circ} \mathrm{C}$.

The strain energy of the $D_{2}$ isomer was calculated to be $501 \mathrm{~kJ} \mathrm{~mol}^{-1}$ using a hypothetical homodesmotic reaction (Supplementary Fig. S7). The strain energy of $\mathbf{3}$ is higher than that of [6]CPP $\left(407 \mathrm{~kJ} \mathrm{~mol}^{-1}\right)$, which is the smallest CPP that has been synthesized to date 20,32 , and even [5]CPP $\left(491 \mathrm{~kJ} \mathrm{~mol}^{-1}\right)^{18,33}$. In contrast, precursor 5 does not exhibit significant strain because the bond angle of cis-substituted platinum would be close to its ideal angle of $90^{\circ}$, although detailed structural analysis has so far proved unsuccessful. These results strongly suggest that the use of reductive elimination is an excellent strategy for synthesizing highly strained molecules.

$\mathbf{X}$-ray crystallographic analysis of $\mathbf{3}$. The structure of $\mathbf{3}$ was unambiguously determined by X-ray crystallographic analysis performed on a single crystal of $\mathbf{3}$ that was grown by vapor diffusion of $n$-hexane into a solution of 3 in $\mathrm{CHCl}_{3}$ (Supplementary Data 1). The crystal belongs to the tetragonal crystal system with a space group of $P \overline{4} 2{ }_{1} c$. As shown in the ORTEP drawing in Fig. 4 a, 3 clearly exhibited a ball-shaped structure, with the inner void space occupied by highly disordered $n$-hexane molecules. The structure of $\mathbf{3}$ was found not to be a highly symmetrical circular shape but an elliptic form, the breadth of which was shown to be elongated along the $c$ axis (15.28(3) $\AA$ ) rather than the $a$ - and $b$ axes (12.54(9) $\AA$ ), as estimated from the distance between the diagonal ipso carbon atoms. The conformation of 3 in the crystal did not have $D_{2}$ symmetry, which was calculated to be the most stable conformer, but instead possessed a pseudo $S_{4}$ symmetry, which was induced by the elongation of the $c$ axis, as a

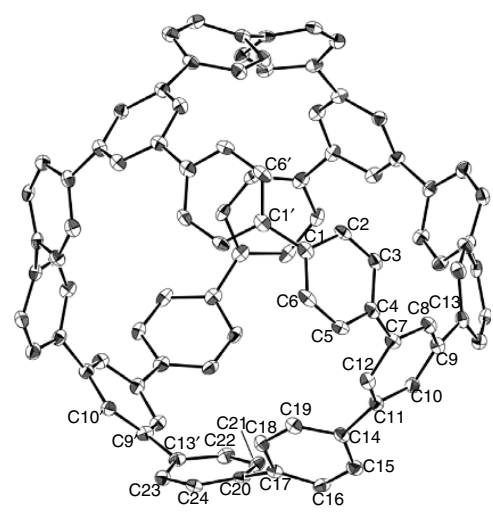

b

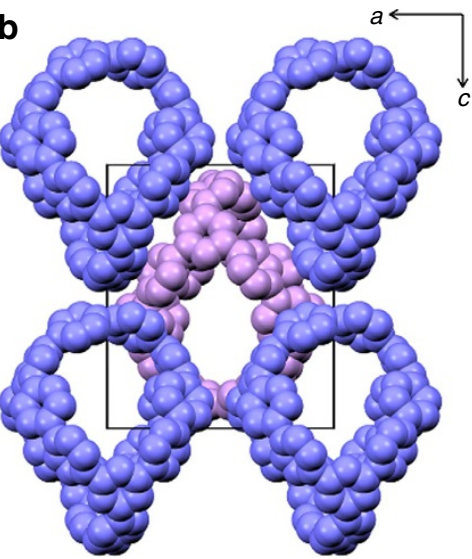

C

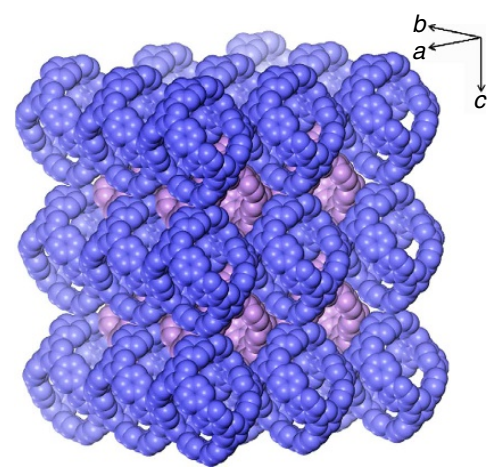

Figure 4 | Crystal structure of 3. (a) ORTEP drawing of 3, showing the atom-numbering scheme. Asterisks indicate atoms generated by the symmetry operation. Thermal ellipsoids are shown at $50 \%$ probability. Hydrogen atoms and solvent atoms are omitted for clarity. Crystal data; tetragonal, $P \overline{4} 2_{1} C$ (\#114): $a=16.0885(6) \AA, b=16.0885(6) \AA, c=18.6558(8) \AA, V=4828.9(3) \AA 3, Z=2, R_{\text {all }}=0.0665, w R_{2}=0.1682$, GOF $=1.068$. (b) Crystal packing of 3. View down $b$ axis. (c) Space filling model in extended area. Carbon atoms are shown as blue or purple and layer structure (one layer in blue and another layers in purple) are presented in the figure. For clarity, hydrogen atoms and solvent molecules are omitted. 
mentioned above. The bond lengths and bond angles of the crystal of 3 were in good agreement with those of the calculated $S_{4}$ structure, but the dihedral angle with respect to the two benzene units was slightly different. This apparent contradiction between the gas phase and crystalline structures is likely to be due to the effects of crystal packing forces and/or inclusion of solvent molecules.

Selected structural parameters of $\mathbf{3}$ obtained from the X-ray analysis and the theoretical calculations are summarized in Supplementary Table S1. The bond lengths of the $\mathrm{C}_{\mathrm{ipso}}-\mathrm{C}_{\mathrm{ipso}}$ bonds, namely $\mathrm{C} 1-\mathrm{Cl}^{*}, \mathrm{C} 4-\mathrm{C} 7, \mathrm{C} 9-\mathrm{C} 13, \mathrm{C} 11-\mathrm{C} 14$ and $\mathrm{C} 17-\mathrm{C} 20$ were in the range of 1.46(4)-1.49(0) $\AA$, the values of which are typical $\mathrm{C}_{\text {ipso }}-\mathrm{C}_{\text {ipso }}$ bond lengths observed between two phenyl groups. The $\mathrm{C}-\mathrm{C}$ bonds of the benzene rings were in the range of $1.37(7)-1.39(6) \AA$, and no significant bond alternation was observed. These results indicate that, despite extremely high strain of 3 , the benzenoid form was preserved in all of the benzene rings. This observation is in sharp contrast to the hexagons of fullerenes and small CPPs, where the benzenoid character is reduced owing to the presence of strain. The ipso carbon atoms were slightly pyramidalized, as indicated by the sum of three bond angles around them being $<360^{\circ}$ (357.4(2)$\left.358.9(2)^{\circ}\right)$. The bend angles as defined by the angle consisting of three ipso carbon atoms ${ }^{33}$, namely $\mathrm{Cl}^{*}-\mathrm{C} 1-\mathrm{C} 4, \mathrm{C} 1-\mathrm{C} 4-\mathrm{C} 7$, C4-C7-C10, C12-C9-C13, C8-C11-C14, C11-C14-C17, $\mathrm{C} 14-\mathrm{C} 17-\mathrm{C} 20, \mathrm{C} 17-\mathrm{C} 20-\mathrm{C} 13^{*}$ and $\mathrm{C} 20-\mathrm{C}_{13}{ }^{*}-\mathrm{C} 9^{*}$ were $155.4(5)^{\circ}, 158.1(1)^{\circ}, 161.7(7)^{\circ}, 161.7(7), 164.6(2)^{\circ}, 161.3(1)^{\circ}$, $163.1(3)^{\circ}, \quad 163.4(7)^{\circ}$ and $160.4(0)^{\circ}$, respectively. These observations suggest that the strain is more localized at the ipso carbons of the paraphenylene unit.

The molecular arrangement of $\mathbf{3}$ in the crystal was found to be a body-centered quasi-cubic structure $(a=b \neq c)$, where each molecule of 3 in the unit cell center had eight nearest upsidedown neighbors on the vertices of the unit cell, as shown in Fig. $4 \mathrm{~b}$ and c. Interestingly, there is no $\pi-\pi$ stacking contact of benzene units between adjacent molecules of 3 . Instead, weak offset $\mathrm{C}-\mathrm{H} / \pi$ interactions were observed between the central molecule and the vertex molecules, in which the $\mathrm{C}-\mathrm{H}$ bonds lay perpendicular to the $\mathrm{C}$ atom of benzene, rather than pointing towards the center of the benzene rings (Supplementary Fig. S8) ${ }^{34}$. The observed $\mathrm{C}-\mathrm{H} \ldots \pi$ bond distances $(3.5-3.6 \AA$ ) were slightly longer than the sum of the van der Waals radius of $\mathrm{sp}^{2} \mathrm{C}$ $(3.40 \AA)$. This type of $\mathrm{C}-\mathrm{H} \ldots \pi$ interaction is observed in crystalline pentacene and is responsible for the large charge mobility in pentacene-based organic transistors ${ }^{35}$. Therefore, 3 might also serve as a new charge transport material in molecular electronics. Indeed, the flash-photolysis time-resolved microwave conductivity measurements ${ }^{36}$ on the solid film of 3 with $7,7,8,8$ tetracyanoquinodimethane gives a clear signature of photoinduced charge separation and the subsequent delocalization of positive charges on 3 , revealing its moderate hole mobility of $3.0 \times 10^{-3} \mathrm{~cm}^{2} \mathrm{~V}^{-1} \mathrm{~s}^{-1}$ (Supplementary Fig. S9).

Physical properties of 3 . The ultraviolet-vis spectrum of $\mathbf{3}$ in chloroform at room temperature shows an absorption maximum at $317 \mathrm{~nm}$, with an absorption coefficient $\varepsilon=29,000 \mathrm{M}^{-1} \mathrm{~cm}^{-1}$ (Supplementary Fig. S10). The time-dependent DFT calculations for the $D_{2}$ and $S_{4}$ isomers indicated that this absorption mainly consisted of four transitions for the $D_{2}$ isomer and three transitions for the $S_{4}$ isomer, but that the HOMO $\rightarrow$ LUMO transition was symmetry-forbidden for both isomers (Supplementary Table S2). In the fluorescence spectra, a blue fluorescence was observed with $\lambda_{\mathrm{em}}=426 \mathrm{~nm}$ in THF. The Stokes shift was significantly high, probably due to large structural relaxation from the FranckCondon state ${ }^{37}$. The fluorescence quantum yield $\left(\Phi_{\mathrm{F}}\right)$ was determined to be 0.44, using 9,10-dicyanoanthracene as a standard. The fluorescence decay of $\mathbf{3}$ followed first-order kinetics with a lifetime $(\tau)=2.1 \mathrm{~ns}$, as measured by the singlephoton counting method. The radiation decay rate constant $\left(k_{\mathrm{r}}\right)$ was determined to be $2.1 \times 10^{8} \mathrm{~s}^{-1}$ from the equation $k_{\mathrm{r}}=\Phi_{\mathrm{F}} / \tau$.

The electrochemical properties of $\mathbf{3}$ were studied using differential pulse voltammetry (DPV) in a $0.1 \mathrm{M}$ solution of $\mathrm{Bu}_{4} \mathrm{NPF}_{6}$ in 1,1,2,2-tetrachloroethane as a supporting electrolyte (Supplementary Fig. S11). A single oxidation peak was observed, with an oxidation potential of $+1.06 \mathrm{~V}$ versus ferrocene/ ferrocenium couple $\left(\mathrm{Fc} / \mathrm{Fc}^{+}\right)$; however, no reduction was observed under the given solvent window.

\section{Discussion}

A ball-like 3D $\pi$-conjugated molecule 3 was successfully synthesized and characterized. The key steps of the synthesis are the platinum-mediated assembly of $\pi$-units by transmetallation and subsequent reductive elimination of the platinum. The assembly process by which the hexanuclear platinum complex $\mathbf{5}$ was formed mimics the self-assembly of metal and ligands that form structurally related cage-like coordination complexes (Fig. 1c). Furthermore, despite the high strain of 3 , reductive elimination of platinum from $\mathbf{5}$ proceeded with reasonable yield. As many metal-organic frameworks with 3D structures are already known and can easily be prepared, the assembly/reductive elimination strategy described here would provide a variety of new 3D $\pi$-conjugated molecules with different structures and topologies, which are challenging to obtain using conventional synthetic methods. In view of the diverse range of possible functions of $\pi$-conjugated molecules, the current method has the potential to open up a new era of $3 \mathrm{D} \pi$-conjugated molecules. Interestingly, as the structure of $\mathbf{3}$ is topologically identical to a Reuleaux triangle, the extension of this synthetic strategy should make it possible to synthesize molecules with Klein's quartic curve structure $^{38}$, a 3D version of a Möbius strip ${ }^{39}$.

While this work was ongoing, Matsui et al. ${ }^{40}$ reported on the synthesis of a $\pi$-conjugated $3 \mathrm{D}$ molecule that possessed a simpler bicyclic structure than $\mathbf{3}$, which is tricyclic, using a modification of the strategy they developed for CPP synthesis. However, the synthesis required long reaction steps and the final product was only obtained in a low overall yield. Furthermore, it is likely that extension of the method to the synthesis of a structurally diverse array of $3 \mathrm{D}$ molecules would be challenging.

\section{Methods}

General. All reaction conditions dealing with air- and moisture-sensitive compounds were carried out in a dry reaction vessel under a nitrogen atmosphere ${ }^{1} \mathrm{H}(400 \mathrm{MHz})$ and ${ }^{13} \mathrm{C} \mathrm{NMR}(100 \mathrm{MHz})$ spectra were measured for a $\mathrm{CDCl}_{3}$ or $\left(\mathrm{CDCl}_{2}\right)_{2}$ solution of a sample and are reported in p.p.m. $(\delta)$ from internal tetramethylsilane or residual solvent peak. ${ }^{19} \mathrm{~F}$ NMR spectra were measured at $376 \mathrm{MHz}$ and are reported in $\delta$ from external $\mathrm{C}_{6} \mathrm{~F}_{6}$ (-162.9 p.p.m.), which was separately calibrated from $\mathrm{CCl}_{3} \mathrm{~F}$ (0.0 p.p.m.). ${ }^{31} \mathrm{P}$ NMR spectra were measured at $162 \mathrm{MHz}$ and are reported from external $85 \% \mathrm{H}_{3} \mathrm{PO}_{4}$ aqueous solution. Infra-red spectrum (absorption) was reported in $\mathrm{cm}^{-1}$. Electrospray ionization time-offlight mass spectrum (ESI-TOF MS) was recorded under the positive mode with samples dissolved in a $\mathrm{CH}_{2} \mathrm{Cl}_{2}$ /isopropanol solution. Matrix-assisted laser-desorption ionization time-of-flight mass spectrum (MALDI-TOF MS) was obtained on a spectrometer under the positive reflection mode with $20 \mathrm{kV}$ acceleration voltage. Samples were prepared by mixing a $1: 1$ ratio of sample $\left(1 \mathrm{mg} \mathrm{ml}^{-1}\right)$ and dithranol $\left(1 \mathrm{mg} \mathrm{ml}^{-1}\right)$ solutions in THF. Ultraviolet-vis and fluorescence spectra were measured in $\mathrm{CHCl}_{3}$ and THF at room temperature, respectively. DPV was performed with a Pt electrode of a sample solution $(1 \mathrm{mM})$ in $0.1 \mathrm{M} \mathrm{Bu}_{4} \mathrm{NPF}_{6}$ solution of 1,1,2,2-tetrachloroethane at room temperature under a nitrogen atmosphere. The scan rate with $20 \mathrm{mV} \mathrm{s}^{-1}$ was employed. After the measurement, ferrocene was added to the mixture and the potential was calibrated with respect to the $\mathrm{Fc} / \mathrm{Fc}^{+}$.

Materials. Unless otherwise noted, commercially available materials were used without purification. Dichloromethane was distilled successively from $\mathrm{P}_{2} \mathrm{O}_{5}$ and $\mathrm{K}_{2} \mathrm{CO}_{3}$ and stored over molecular sieves. Toluene was distilled from $\mathrm{CaH}_{2}$ and 
stored over molecular sieves. Pt(cod) $\mathrm{Cl}_{2}$ (ref. 41), dppf (ref. 42), 1,3,5-tris ( $p$ bromophenyl)benzene $\mathbf{4 a}$ (ref. 43) are commercially available and were easily synthesized as reported. ${ }^{1} \mathrm{H}$ NMR and ${ }^{13} \mathrm{C}$ NMR spectra are provided for all new compounds (see Supplementary Figs S12-S17).

Synthesis of $\mathbf{4 b}$. To a solution of $\mathbf{4 a}(5.43 \mathrm{~g}, 10 \mathrm{mmol})$ in THF $(75 \mathrm{ml}) \mathrm{BuLi}$ $\left(32 \mathrm{ml}, 1.41 \mathrm{M}\right.$ in hexane, $45 \mathrm{mmol}$ ) was slowly added by using a syringe at $-78^{\circ} \mathrm{C}$. After stirring for $1 \mathrm{~h}$ at this temperature, a solution of trimethylstannyl chloride $(8.96 \mathrm{~g}, 45 \mathrm{mmol})$ in THF $(10 \mathrm{ml})$ was slowly added through a cannula at $-78^{\circ} \mathrm{C}$ and the resulting mixture was slowly warmed to room temperature over $3 \mathrm{~h}$. After stirring for $3 \mathrm{~h}$ at this temperature, the reaction mixture was quenched with saturated aqueous $\mathrm{NH}_{4} \mathrm{Cl}$ solution and was extracted with ethyl acetate. The combined organic layer was washed with brine, dried over $\mathrm{MgSO}_{4}$, filtered and concentrated under reduced pressure to give a crude mixture. The residue was purified by passing neutral alumina with hexane as an eluent to give the title compound $(7.22 \mathrm{~g}, 91 \%)$ as a white solid. ${ }^{1} \mathrm{H}$ NMR $\left(\mathrm{CDCl}_{3}, 400 \mathrm{MHz}\right) 0.34(\mathrm{~s}, 27 \mathrm{H}$, $\left.J_{\mathrm{Sn}-\mathrm{H}}=54.0 \mathrm{~Hz}, \mathrm{SnMe}_{3}\right), 7.62(\mathrm{~d}, J=7.6 \mathrm{~Hz}, 6 \mathrm{H},-\mathrm{ArH}), 7.66(\mathrm{~d}, J=7.2 \mathrm{~Hz}, 6 \mathrm{H},-$ $\mathrm{ArH}), 7.77(\mathrm{~s}, 3 \mathrm{H},-\mathrm{ArH}) ;{ }^{13} \mathrm{C}$ NMR $\left(\mathrm{CDCl}_{3}, 100 \mathrm{MHz}\right)-9.50\left(J_{\mathrm{Sn}-\mathrm{C}}=341.5 \mathrm{~Hz}\right)$, $125.18,126.92,136.35,141.04,141.50,142.36$; HRMS (FAB) $\mathrm{m} / z$ : calcd for $\mathrm{C}_{33} \mathrm{H}_{42} \mathrm{Sn}_{3}(\mathrm{M})^{+}$, , 798.0352; found 798.0285; IR (KBr) 798, 990, 1,265 1,420, 1,465, $1,571,2,900,3,002 ; \mathrm{mp} 191.0-193.5^{\circ} \mathrm{C}$.

Synthesis of 4c. $\mathrm{Pt}(\operatorname{cod}) \mathrm{Cl}_{2}(2.24 \mathrm{~g}, 6.0 \mathrm{mmol})$ and $\mathbf{4 b}(1.59 \mathrm{~g}, 2.0 \mathrm{mmol})$ were dissolved in 1,2 -dichloroethane $(1,200 \mathrm{ml})$ and the mixture was heated at $50^{\circ} \mathrm{C}$ for $20 \mathrm{~h}$ under a nitrogen atmosphere. The solvent was removed under reduced pressure and the residue was washed with toluene to give a crude mixture. The residue was purified by passing over a short neutral alumina plug with $\mathrm{CH}_{2} \mathrm{Cl}_{2}$ as an eluent to give the title compound $(2.16 \mathrm{~g}, 82 \%)$ as a white solid. ${ }^{1} \mathrm{H}$ NMR $\left(\mathrm{CDCl}_{3}, 400 \mathrm{MHz}\right) 2.15-2.84(\mathrm{~m}, 24 \mathrm{H}, \mathrm{cod}), 4.65$ (s, $\left.J_{\mathrm{Pt}-\mathrm{C}}=68.5 \mathrm{~Hz}, 6 \mathrm{H}, \mathrm{cod}\right), 5.81$ (s, 6H, cod), 7.27-7.36 (m, 3H, -ArH), 7.36-7.49 (m, 6H, -ArH), 7.61-7.76 (m, 6H, $-\mathrm{ArH}) ;{ }^{13} \mathrm{C}$ NMR $\left(\mathrm{CDCl}_{3}, 100 \mathrm{MHz}\right) 27.91,32.13,87.44\left(J_{\mathrm{CPt}}=201.3\right), 115.70$, 124.30, 124.66, 127.11, 127.23, 128.71, 134.21, 137.28, 141.39, 141.84, 142.21,

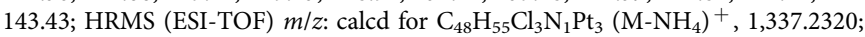
found 1,337.2402; IR (KBr) 772, 890, 986, 1,215, 1,460, 1,536, 2,221, 2,765, 2,980.

Synthesis of 5d. The solution of $4 \mathrm{~b}(0.40 \mathrm{~g}, 0.5 \mathrm{mmol})$ and $4 \mathrm{c}(0.66 \mathrm{~g}, 0.5 \mathrm{mmol})$ in 1,2-dichloroethane $(1,500 \mathrm{ml})$ was heated at $50^{\circ} \mathrm{C}$ for $30 \mathrm{~h}$ under a nitrogen atmosphere, forming a white precipitate. The solvent was removed under reduced pressure and the residue was washed with 1,2-dichloroethane/toluene (1/1) to give the title compound $(0.61 \mathrm{~g}, 81 \%)$ as a white solid. ${ }^{1} \mathrm{H}$ NMR $\left(\mathrm{C}_{2} \mathrm{D}_{2} \mathrm{Cl}_{4}, 400 \mathrm{MHz}\right)$ 2.17-2.65 (brs, $48 \mathrm{H}$, cod), 4.84-5.27 (brs, $24 \mathrm{H}, \mathrm{cod}$ ), 7.18-7.23 (m, 24H, $-\mathrm{ArH}$ ), 7.24-7.32 (m, 36H, -ArH); ${ }^{13} \mathrm{C}$ NMR $\left(\mathrm{C}_{2} \mathrm{D}_{2} \mathrm{Cl}_{4}, 100 \mathrm{MHz}\right) 30.48,104.03,126.83$, $128.82,130.05,134.37,135.55,156.22$; IR (KBr) 789, 988, 1,020, 1,088, 1,465, 1,568, $2,360,2,868,2,996$.

Synthesis of 3. A suspension of $\mathbf{5 d}(0.30 \mathrm{~g}, 0.1 \mathrm{mmol})$ and dppf $(0.33 \mathrm{~g}, 0.6 \mathrm{mmol})$ in $\mathrm{CH}_{2} \mathrm{Cl}_{2}(300 \mathrm{ml})$ was stirred at room temperature for $19 \mathrm{~h}$ under a nitrogen atmosphere. The solvent was removed under reduced pressure and the residue was washed with ethyl acetate to give $\mathbf{5 e}(0.49 \mathrm{~g}, 86 \%)$ as an orange solid. The suspension of $5 \mathbf{e}(0.49 \mathrm{~g}, 0.086 \mathrm{mmol})$ and $\mathrm{XeF}_{2}(87.4 \mathrm{mg}, 0.52 \mathrm{mmol})$ in toluene $(86 \mathrm{ml})$ was heated at $90^{\circ} \mathrm{C}$ for $20 \mathrm{~h}$ under a nitrogen atmosphere. The resulting suspension was filtered and the filtrate was concentrated under reduced pressure to give a crude mixture. The residue was purified by silica gel chromatography (hexane $/ \mathrm{CH}_{2} \mathrm{Cl}_{2}=4 / 1$ to $\left.1 / 1\right)$ to give $3(21.9 \mathrm{mg}, 21 \%$ ) as a pale yellow solid. ${ }^{1} \mathrm{H} \mathrm{NMR}\left(\mathrm{CDCl}_{3}, 400 \mathrm{MHz}\right) 7.41$ (d, $\left.24 \mathrm{H}, J=8.0 \mathrm{~Hz},-\mathrm{ArH}\right), 7.54(\mathrm{~s}, 12 \mathrm{H},-\mathrm{ArH})$, $7.59(\mathrm{~d}, 24 \mathrm{H}, J=8.0 \mathrm{~Hz},-\mathrm{ArH}) ;{ }^{13} \mathrm{C}$ NMR $\left(\mathrm{CDCl}_{3}, 100 \mathrm{MHz}\right) 125.45,127.36$, $128.26,138.55,139.52,141.89$; HRMS (MALDI-TOF) $m / z$ : calcd for $\mathrm{C}_{96} \mathrm{H}_{60}[\mathrm{M}]^{+}$: $1,212.4612$; found $1,212.4690$.

Alternative synthesis of 3. A suspension of $\mathbf{5 d}(30.3 \mathrm{mg}, 10 \mu \mathrm{mol})$ and dppf (33.3 g, $60 \mu \mathrm{mol})$ in $\mathrm{CH}_{2} \mathrm{Cl}_{2}(30 \mathrm{ml})$ was stirred at room temperature for $19 \mathrm{~h}$ under a nitrogen atmosphere. The solvent was removed under reduced pressure and the residue was washed with ethyl acetate to give $5 \mathbf{e}(48.0 \mathrm{mg}, 84 \%)$ as an orange solid. The suspension of $5 \mathbf{e}(48.0 \mathrm{mg}, 8.4 \mu \mathrm{mol})$ and $\mathrm{PPh}_{3}(26.4 \mathrm{mg}, 101 \mu \mathrm{mol})$ in toluene $(8.4 \mathrm{ml})$ was heated at $90^{\circ} \mathrm{C}$ for $20 \mathrm{~h}$ under a nitrogen atmosphere. The resulting suspension was filtered off and the filtrate was concentrated under reduced pressure to give a crude mixture. The residue was purified by silica gel chromatography (hexane/ $\mathrm{CH}_{2} \mathrm{Cl}_{2}=4 / 1$ to $\left.1 / 1\right)$ to give $3(1.9 \mathrm{mg}, 19 \%$ ) as a pale yellow solid.

NMR monitoring of the reductive elimination of $5 e$. To a solution of $5 e(6.4 \mathrm{mg}$, $1.12 \mu \mathrm{mol})$ in toluene- $\mathrm{d}_{8}(0.5 \mathrm{ml})$ in a NMR tube $\mathrm{XeF}_{2}\left(67 \mu \mathrm{l}, 0.1 \mathrm{M}\right.$ in toluene- $\mathrm{d}_{8}$, $6.72 \mu \mathrm{mol}$ ) was added at room temperature. The ${ }^{19} \mathrm{~F}$ and ${ }^{31} \mathrm{P}$ NMR analyses showed the quantitative conversion from $5 e\left({ }^{31} \mathrm{P}\right.$ NMR; 20.3 p.p.m., ${ }^{1} J_{\mathrm{PtP}}=$ $1,784.3 \mathrm{~Hz})$ to the Pt(IV) difluoride complex $\left({ }^{19} \mathrm{~F}\right.$ NMR; -271.3 p.p.m., ${ }^{31} \mathrm{P}$ NMR; -2.9 p.p.m., ${ }^{1} J_{\mathrm{PtP}}=1,018.0 \mathrm{~Hz}$ ). The NMR tube was sealed and was heated at $90{ }^{\circ} \mathrm{C}$. The progress of the reaction was monitored by ${ }^{19} \mathrm{~F}$ and ${ }^{31} \mathrm{P}$ NMR spectrometry after 3,9 and $18 \mathrm{~h}$. The disappearance of $\mathbf{5 e}$ and the formation of several species were observed at 3 and $9 \mathrm{~h}$ and the reaction eventually gave Pt(dppf) $F_{2}\left({ }^{19}\right.$ F NMR; 233.1 p.p.m., ${ }^{31}$ P NMR; 9.5 p.p.m., $\left.{ }^{1} J_{\mathrm{PtP}}=3542.3 \mathrm{~Hz}\right)$ as an exclusive product.

Computational study. DFT calculations were carried out by using the Gaussian 09 program package ${ }^{44}$. The DFT method with the B3LYP hybrid functional ${ }^{45,46}$ and the $6-31 \mathrm{G}(\mathrm{d})$ basis set ${ }^{47}$ was employed. Geometry optimizations were performed under the constraint of $D_{2}, S_{4}, C_{1}, C_{2}, C_{3}$ or $T$ symmetries. Normal coordinate analysis at the same level of theory was performed, and the number of imaginary frequencies was 0 for all structures. See Supplementary Figs S18 and S19 and Supplementary Tables S3 and S4.

X-ray crystallography. Single-crystal X-ray diffraction experiments were carried out with a large cylindrical imaging plate camera ${ }^{48}$ at SPring-8 beam line BL02B1 (Hyogo, Japan). Crystal data are summarized in Supplementary Table S5. The structures were solved by the direct methods with SIR2004 (ref. 49) and refined by the full-matrix least-squares techniques against $F 2$ (SHELXL-97) ${ }^{50}$. The intensities were corrected for Lorentz and polarization effects. The non-hydrogen atoms were refined anisotropically. Hydrogen atoms were placed using AFIX instructions. All calculations were performed by using Crystal Structure 4.0 or Yadokari-XG 2011.

Charge carrier mobility in $\mathbf{3}$. Charge carrier mobility in $\mathbf{3}$ was measured by the flash-photolysis time-resolved microwave (FP-TRMC) technique ${ }^{36,51} .3(5 \mathrm{mg}, 2.5$ wt $\%$ ) and 7,7,8,8-tetracyanoquinodimethane ( $5 \mathrm{mg}, 2.5 \mathrm{wt} \%$ ) were added to $200 \mathrm{mg}$ of toluene solution including $5 \mathrm{wt} \%$ of poly(methyl methacrylate). The mixture was heated at $80^{\circ} \mathrm{C}$, casted onto a quartz substrate and dried at room temperature. The nanosecond laser pulses from an Nd: YAG laser (third harmonic generation, THG $(355 \mathrm{~nm})$ from Spectra Physics, INDI-HG, FWHM $4 \mathrm{~ns}$ ) was used as excitation source. The excitation density was $4.6 \times 10^{15}$ photons $\mathrm{cm}^{-2}$. The resonant frequency and the microwave power were set at $\sim 9.1 \mathrm{GHz}$ and $3 \mathrm{~mW}$, respectively The TRMC signal from a diode was recorded on a digital oscilloscope (Tektronix TDS 3032B). The transient photoconductivity $(\Delta \sigma)$ of the samples is related to the reflected microwave power $\left(\Delta P_{\mathrm{r}} / P_{\mathrm{r}}\right)$ and sum of the mobilities of charge carriers via:

$$
\begin{gathered}
<\Delta \sigma>=\frac{1}{A} \frac{\Delta P_{\mathrm{r}}}{P_{\mathrm{r}}} \\
<\Delta \sigma>=e \Phi N \sum \mu
\end{gathered}
$$

where $A, e, \Phi, N$ and $\sum \mu$ are the sensitivity factor, elementary charge of electron, photo carrier generation yield (quantum efficiency), the number of absorbed photons per unit volume, and sum of mobilities for negative and positive carriers, respectively. The value of $\Phi$ was determined by transient absorption spectroscopy measurement. Details of the experimental setup are described elsewhere ${ }^{36}$.

Time-dependent absorption spectral changes were monitored by Hamamatsu C7700 streak camera via a Hamamatsu C5094 spectrometer upon direct excitation of the identical solid-state films used for TRMC measurements using a third harmonic generation $\left(\lambda=355 \mathrm{~nm}, 50 \mathrm{~mJ}\right.$ pulse $\left.\mathrm{s}^{-1} \mathrm{~cm}^{-2}\right)$ from the Nd: YAG laser. To correct a 2D time-wavelength correlation data of the transient absorption, the streak scope images were averaged over 2,500 images via a high-speed camera (Hamamatsu C4742-95).

\section{References}

1. Kroto, H. W., Heath, J. R., O’Brien, S. C., Curl, R. F. \& Smalley, R. E. $\mathrm{C}_{60}$ : Buckminsterfullerene. Nature 318, 162-163 (1985).

2. Iijima, S. Helical microtubules of graphitic carbon. Nature 354, 56-58 (1991).

3. Guldi, D. M. \& Martín, N. (eds) Carbon Nanotubes and Related Structures (Wiley-VCH, 2010).

4. Akasaka, T., Wudl, F. \& Nagase, S. (eds) Chemistry of Nanocarbons (John Wiley \& Sons, 2010).

5. Brabec, C. J. Organic photovoltaics: technology and market. Solar Energy Mater. Solar Cells 83, 273-292 (2004).

6. Brabec, C. J. et al. Polymer-fullerene bulk-heterojunction solar cells. Adv Mater. 22, 3839-3856 (2010).

7. Collins, P. G. \& Avouris, P. Nanotubes for electronics. Sci. Am. 283, 62-69 (2000).

8. Scott, L. T. et al. A rational chemical synthesis of $\mathrm{C}_{60}$. Science 295, 1500-1503 (2002).

9. Tahara, K. \& Tobe, Y. Molecular loops and belts. Chem. Rev. 106, 5274-5290 (2006).

10. Jasti, R., Bhattacharjee, J., Neaton, J. B. \& Bertozzi, C. R. Synthesis, characterization, and theory of [9]-, [12]-, and [18]cycloparaphenylene: carbon nanohoop structures. J. Am. Chem. Soc. 130, 17646-17647 (2008).

11. Takaba, H., Omachi, H., Yamamoto, Y., Bouffard, J. \& Itami, K. Selective synthesis of [12] cycloparaphenylene. Angew. Chem. Int. Ed. 48, 6112-6116 (2009). 
12. Yamago, S., Watanabe, Y. \& Iwamoto, T. Synthesis of [8]cycloparaphenylene from a square-shaped tetranuclear platinum complex. Angew. Chem. Int. Ed. 49, 757-759 (2010)

13. Jasti, R. \& Bertozzi, C. R. Progress and challenges for the bottom-up synthesis of carbon nanotubes with discrete chirality. Chem. Phys. Lett. 494, 1-7 (2010).

14. Sisto, T. J. \& Jasti, R. Overcoming molecular strain: synthesis of [7]cycloparaphenylene. Synlett. 23, 483-489 (2012).

15. Hirst, E. S. \& Jasti, R. Bending benzene: syntheses of [n]cycloparaphenylenes. J. Org. Chem. 77, 10473-10478 (2012).

16. Itami, K. Toward controlled synthesis of carbonnanotubes and graphenes. Pure Appl. Chem. 84, 907-916 (2012).

17. Omachi, H., Segawa, Y. \& Itami, K. Synthesis of cycloparaphenylenes and related carbon nanorings: a step toward the controlled synthesis of carbon nanotubes. Acc. Chem. Res. 45, 1378-1389 (2012).

18. Iwamoto, T., Watanabe, Y., Sakamoto, Y., Suzuki, T. \& Yamago, S. Selective and random syntheses of $[n]$ cycloparaphenylenes $(n=8-13)$ and size dependence of their electronic properties. J. Am. Chem. Soc. 133, 8354-8361 (2011).

19. Kayahara, E., Sakamoto, Y., Suzuki, T. \& Yamago, S. Selective synthesis and crystal structure of [10]cycloparaphenylene. Org. Lett. 14, 3284-3287 (2012).

20. Kayahara, E., Iwamoto, T., Suzuki, T. \& Yamago, S. Selective synthesis of [6]-, [8]-, and [10]cycloparaphenylenes. Chem. Lett. 42, 621-623 (2013).

21. Fujita, M., Yazaki, J. \& Ogura, K. Preparation of a macrocyclic polynuclear complex, $\left[(\text { en }) \operatorname{Pd}\left(4,4^{\prime} \text {-bpy }\right)\right]_{4}\left(\mathrm{NO}_{3}\right)_{8}$ (en = ethylenediamine, bpy = bipyridine), which recognizes an organic molecule in aqueous media. J. Am. Chem. Soc. 112, 5645-5647 (1990)

22. Fujita, M., Yazaki, J. \& Ogura, K. Spectroscopic observation of self-assembly of a macrocyclic tetranuclear complex composed of $\mathrm{Pt}^{2+}$ and 4,4'-bipyridine. Chem. Lett. 20, 1031-1032 (1991).

23. Stang, P. J. \& Cao, D. H. Transition metal based cationic molecular boxes. Selfassembly of macrocyclic platinum(II) and palladium(II) tetranuclear complexes. J. Am. Chem. Soc. 116, 4981-4982 (1994).

24. Fujita, M. et al. Self-assembly of ten molecules into nanometre-sized organic host frameworks. Nature 378, 469-471 (1995).

25. Fujita, M. Metal-directed self-assembly of two- and three-dimensional synthetic receptors. Chem. Soc. Rev. 27, 417-425 (1998).

26. Fujita, M., Tominaga, M., Hori, A. \& Therrien, B. Coordination assemblies from a Pd(II)-cornered square complex. Acc. Chem. Res. 38, 369-378 (2005).

27. Seidel, S. R. \& Stang, P. J. High-symmetry coordination cages via self-assembly. Acc. Chem. Res. 35, 972-983 (2002).

28. Yahav, A., Goldberg, I. \& Vigalok, A. Synthesis of the elusive $\left(\mathrm{R}_{3} \mathrm{P}\right)_{2} \mathrm{MF}_{2}$ $(\mathrm{M}=\mathrm{Pd}, \mathrm{Pt})$ complexes. J. Am. Chem. Soc. 125, 13634-13635 (2003).

29. Yahav, A., Goldberg, I. \& Vigalok, A. Difluoro complexes of platinum(II) and (IV) with monodentate phosphine ligands: an exceptional stability of $\mathrm{d}^{6}$ octahedral organometallic fluorides. Inorg. Chem. 44, 1547-1553 (2005).

30. Yahav-Levi, A., Goldberg, I., Vigalok, A. \& Vedernikov, A. N. Competitive aryl-iodide vs. aryl-aryl reductive elimination reactions In $\mathrm{Pt}(\mathrm{IV})$ complexes: experimental and theoretical studies. J. Am. Chem. Soc. 130, 724-731 (2008)

31. Fujitsuka, M., Iwamoto, T., Kayahara, E., Yamago, S. \& Majima, T. Enhancement of the quinoidal character for smaller [n]cycloparaphenylenes probed by Raman spectroscopy. Chem. Phys. Chem. 14, 1570-1572 (2013).

32. Xia, J. \& Jasti, R. Synthesis, characterization, and crystal structure of [6]cycloparaphenylene. Angew. Chem. Int. Ed. 124, 2524-2526 (2012).

33. Bachrach, S. M. \& Stück, D. DFT study of cycloparaphenylenes and heteroatom-substituted nanohoops. J. Org. Chem. 75, 6595-6604 (2010).

34. Nishio, M., Hirota, M. \& Umezawa, Y. The $\mathrm{CH} / \pi$ Interaction: Evidence, Nature, and Consequences 91-285 (Pergamon Press, 1998).

35. Valeev, E. F., Coropceanu, V., da Silva Filho, D. A., Salman, S. \& Brédas, J.-L. Effect of electronic polarization on charge-transport parameters in molecular organic semiconductors. J. Am. Chem. Soc. 128, 9882-9886 (2006).

36. Saeki, A., Seki, S., Sunagawa, T., Ushida, K. \& Tagawa, S. Charge-carrier dynamics in polythiophene films studied by in-situ measurement of flashphotolysis time-resolved microwave conductivity (FP-TRMC) and transient optical spectroscopy (TOS). Philos. Mag. 86, 1261-1276 (2006).

37. Fujitsuka, M., Cho, D. W., Iwamoto, T., Yamago, S. \& Majima, T. Sizedependent fluorescence properties of $[n]$ cycloparaphenylenes $(n=8-13)$, hoopshaped $\pi$-conjugated molecules. Phys. Chem. Chem. Phys. 14, 14585-14588 (2012).

38. Moon, F. C. The Machines of Leonardo Da Vinci and Franz Reuleaux: Kinematics of Machines from the Renaissance to MACHINES OF LEONARDO
DA VINCI (History of Mechanism and Machine Science) (Springer-Verlag $\mathrm{GmbH}, 2007)$.

39. Ajami, D., Oeckler, O., Simon, A. \& Herges, R. Synthesis of a Mobius aromatic hydrocarbon. Nature 426, 819-821 (2003).

40. Matsui, K., Segawa, Y., Namikawa, T., Kamada, K. \& Itami, K. Synthesis and properties of all-benzene carbon nanocages: a junction unit of branched carbon nanotubes. Chem. Sci. 4, 84-88 (2013).

41. Hill, G. S. et al.in Inorg. Synth. 149-153 (John Wiley \& Sons, Inc., 2007).

42. Cullen, W. R., Kim, T. J., Einstein, F. W. B. \& Jones, T. Structure of the hydrogenation catalyst $[(\mathrm{PP}) \mathrm{Rh}(\mathrm{NBD})] \mathrm{ClO}_{4}, \mathrm{PP}=\left(\eta^{5}-\left(\mathrm{Me}_{3} \mathrm{C}\right)_{2} \mathrm{PC}_{5} \mathrm{H}_{4}\right)_{2} \mathrm{Fe}$, and some comparative rate studies. Organometallics 2, 714-719 (1983).

43. Zhao, Y. et al. PTSA-catalyzed green synthesis of 1,3,5-triarylbenzene under solvent-free conditions. Green Chem. 12, 1370-1372 (2010).

44. Frisch, M. J. et al. Gaussian 09, Revision A.02 (Gaussian Inc, 2009).

45. Becke, A. D. Density-functional thermochemistry. III. The role of exact exchange. J. Chem. Phys. 98, 5648-5652 (1993).

46. Lee, C., Yang, W. \& Parr, R. G. Development of the Colle-Salvetti correlationenergy formula into a functional of the electron density. Phys. Rev. B 37, 785-789 (1988).

47. Hehre, W. J., Radom, L., Schleyer, P. v. R. \& Pople, J. A. Ab initio Molecular Orbital Theory (John Wiley, 1986).

48. Sugimoto, K. et al. Extremely high resolution single crystal diffractometory for orbital resolution using high energy synchrotron radiation at SPring-8. AIP Conf. Proc. 1234, 887-890 (2010).

49. Burla, M. C. et al. SIR2004: an improved tool for crystal structure determination and refinement. J. Appl. Cryst. 38, 381-388 (2005).

50. Sheldrick, G. M. (ed) SHELXS97. Program for the Solution of Crystal Structures (University of Göttingen, 1997).

51. Valeev, E. F., Coropceanu, V., da Silva Filho, D. A., Salman, S. \& Brédas, J.-L. Effect of electronic polarization on charge-transport parameters in molecular organic semiconductors. J. Am. Chem. Soc. 128, 9882-9886 (2006).

\section{Acknowledgements}

This work was partly supported by the CREST program of the Japan Science and Technology Agency (S.Y.) and by a Grant-in-Aid for Young Scientists (B) from the Japan Society for the Promotion of Science (E.K.). Single-crystal X-ray analysis was performed at BL02B1 of SPring-8 with the approval of Japan Synchrotron Radiation Research Institute (JASRI) (2012B1790). We thank Dr Kunihisa Sugimoto (JASRI) and Dr Katsuhiro Isozaki (Kyoto University) for their guidance and valuable discussions on the $\mathrm{X}$-ray crystallographic analysis.

\section{Author contributions}

S.Y. conceived, designed and directed the investigations and wrote the manuscript with revision provided from E.K. and H.T. The synthetic experiment was carried out by E. K. Single-crystal X-ray analysis was performed by E.K., T.I., and H.T. with helps from N.Y. Computational studies were performed by E.K. and T.S. Raman and fluorescence analyses were carried out by M.F. and T.M. Conductivity measurements were carried out by N.M. and S.S. All authors discussed the results and commented on the manuscript.

\section{Additional information}

Accession codes: The X-ray crystallographic coordinates for structures reported in this Article have been deposited at the Cambridge Crystallographic Data Centre (CCDC) under deposition numbers CCDC 924350. These data can be obtained free of charge from The Cambridge Crystallographic Data Centre via www.ccdc.cam.ac.uk/ data_request/cif.

Supplementary Information accompanies this paper at http://www.nature.com/ naturecommunications

Competing financial interests: The authors declare no competing financial interests.

Reprints and permission information is available online at http://npg.nature.com/ reprintsandpermissions/

How to cite this article: Kayahara, E. et al. Synthesis and physical properties of a ball-like three-dimensional $\pi$-conjugated molecule. Nat. Commun. 4:2694 doi: $10.1038 /$ ncomms3694 (2013). 